\title{
Emergência e uso da perífrase conjuncional no que: gramaticalização, polissemia e argumentação
}

\section{Emergence and Use of the Conjunctional Periphrasis no que: Grammaticalization, Polissemy and Argumentation}

Sanderléia Roberta Longhin

Universidade Estadual Paulista, São José do Rio Preto, São Paulo, Brasil. longhin@ibilce.unesp.br

Resumo: Neste trabalho, investigo as construções de junção mobilizadas pela perífrase no que, entendendo-as como uma instância recente de gramaticalização que contribui para ampliação do repertório conjuncional do português brasileiro. Com base em dados de no que extraídos de textos narrativos, procedentes de enunciação falada e escrita, busco consolidar dois objetivos: (i) descrever aspectos do processo de constituição de no que como juntor perifrástico, particularmente no que toca à reanálise sintagmática e à emergência dos sentidos; e, (ii) analisar as condições de uso de no que, visando a explicitar a manobra argumentativa que singulariza o juntor e que ajuda a compreender suas motivações de uso. Palavras-chave: Gramaticalização; Junção; Polissemia; Argumentação.

\begin{abstract}
In this work I investigate junction constructions mobilized by the periphrasis no que, considering them as a recent instance of grammaticalization that contributes to enhance the conjunctional repertoire of Brazilian Portuguese. Based on no que data extracted from narrative texts, both from spoken and written enunciations, I seek to achieve two goals: (i) describe aspects of the no que constitution process as a periphrastic junctor, particularly with regard to the syntagmatic reanalysis and the emergence of meanings; and (ii) analyze the use
\end{abstract}


conditions of no que with the purpose of elaborating on the argumentative maneuver which singularizes the junctor and helps understand its use motivations.

Keywords: Grammaticalization; Junction; Polyssemy; Argumentation.

Recebido em 19 de fevereiro de 2014.

Aprovado em 11 de junho de 2014.

\section{Introdução}

É fato conhecido que as línguas renovam constantemente seus meios de expressão gramatical e que essa renovação procede, em consonância com o princípio de economia, da utilização de formas velhas para propósitos novos (HOPPER; TRAUGOTT, 1993, p. 64). Também é sabido que, nas línguas, um domínio particularmente predisposto à renovação é aquele dos juntores (MEILLET, 1912). Em português, os historiadores da língua (ALI, 1964; CÂMARA, 1979) mostram que, apesar da herança latina diminuta, houve uma contínua recomposição do quadro conjuncional, por meio de processos de mudança, sobretudo mudanças por gramaticalização, que reanalisam a categoria e o sentido de palavras já existentes.

Em trabalho tipológico sobre gramaticalização de conjunções em línguas europeias, Kortmann (1997) concluiu que as classes de palavras que funcionam como ponto de partida para formação de juntores novos são, mais frequentemente, palavras já gramaticais, tais como advérbios, preposições, complementizadores e relativizadores. Concluiu também que a tendência à constituição de perífrases conjuncionais baseadas em $x+q u e$ é bastante fértil, sendo $x$ uma variável preenchida por palavras de classes diversas. A esse respeito, Kortmann (1997), Halliday (1985), Hagège (2001) e Heine e Kuteva (2007) fazem predições sobre a natureza morfossintática da variável e, a partir de evidências empíricas, sustentam a existência de três canais mais importantes de derivação: nominal, verbal e adverbial. Sobre o canal nominal, relevante para este trabalho, os autores constatam que nomes de sentido genérico (espacial, temporal, modal) tendem a dar lugar a conjunções, por meio de processos históricos tipicamente unidirecionais. Kortmann (1997), em particular, destaca a frequência com que núcleos nominais de orações relativas se 
desenvolvem em juntores causais, condicionais e contrastivos ${ }^{1}$.

No presente trabalho, privilegio uma construção perifrástica peculiar que não apresenta o nome genérico. Analiso ocorrências em que no e que são contíguos e formam uma perífrase conjuncional, conforme (01) e (02), extraídas do Banco de Dados Iboruna. Nessas ocorrências, no que estabelece entre as orações um sentido temporal, sendo possível paráfrase com quando, ainda que a sinonímia não seja perfeita.

(01) ele tava indo embora no que ele saiu da cidade, uma cidade de Minas, o carro quebrou. (Iboruna/AC-075)

(02) meu pai conta... que ele iscou com uma... eu nem sei como que chama a isca que ele põe no peixe... espadinha (se eu não tô enganada) parece uma enguia... ele iscou... e jogou... e ele joga... BEM longe... e vai deixando a isca correr... só que no que ele jogou passou um pássaro... (Iboruna/AC-086)

A partir de evidências de cunho filogenético e ontogenético, Kortmann (1997, p. 155) afirma que o inventário de conjunções temporais nas línguas é prototipicamente estável e comporta itens que são, ao mesmo tempo, os mais antigos e os primeiros a serem adquiridos. Desse ponto de vista, a emergência recente de no que no quadro das conjunções temporais do português estaria em descompasso com essas tendências, o que permite indagar sobre o esquema interpretativo que estaria em jogo com no que e que justificaria sua emergência. Assumo que há uma

\footnotetext{
${ }^{1}$ Longhin-Thomazi (2011) mostrou que a construção (na) hora que está perdendo a composicionalidade, isto é, a percepção de que se trata de um nome em contexto de sintagma preposicional modificado por uma oração relativa, e sendo reanalisada como um juntor que mobiliza um esquema hipotático no qual a oração modificadora acrescenta à oração núcleo nuanças variadas de sentido, que circulam pelos domínios de tempo, causa e condição. As construções com hora, dia, época e semana foram objeto de estudo de Paiva e Pereira (2004) que colocam em questão o estatuto sintático das construções, como oração encaixada adjetiva ou como oração hipotática temporal. A partir da análise de propriedades gramaticais e semânticas das construções, as autoras defenderam os arranjos hipotáticos. Amorim (2013), por sua vez, reuniu indícios sincrônicos do processo de gramaticalização ainda incipiente da locução por causa que.
} 
diferença essencial entre os usos de no que e de quando e que ela reside na propriedade pragmática, peculiar a no que, de 'dramatizar' ou pôr em foco o conteúdo subsequente, por meio da ativação de expectativas e suspense, como será explicitado ao longo deste trabalho.

Tendo em vista que no que não é uma conjunção reconhecida pela tradição gramatical, que no que apresenta uma constituição estrutural atípica com ausência de nome genérico, que possivelmente se especialize na codificação de certas relações temporais e que se apresenta como um marcador de subjetividade, o presente trabalho persegue dois objetivos maiores: (i) fornecer evidências do processo de constituição de no que como juntor; e, (ii) descrever o funcionamento sintático, semântico e pragmático de no que, no âmbito da junção oracional. Trata-se não só de legitimar definitivamente o estatuto de no que como juntor novo, mas de compreender as motivações que levam o falante/escrevente a lançar mão de no que, e não de outro juntor, no extenso paradigma das conjunções temporais.

O uso conjuncional de no que é abordado aqui como um caso de gramaticalização em curso. A perspectiva metodológica é sincrônica e se justifica no propósito de descrever os padrões fluidos de no que e de examinar a possibilidade de ordená-los em um cline de gramaticalidade. A expectativa é a de que os padrões mais abstratizados e subjetivizados sejam mais tardios e se situem mais à direita do cline (TRAUGOTT; KÖNIG, 1991; TRAUGOTT; DASHER, 2002). Assim, aproximo-me de Kortmann (1997, p. 176) para quem os sentidos sincronicamente relacionados também o são diacronicamente, uma vez que, a partir de sentidos derivados, verificados no viés sincrônico, podemos extrair pistas para reconstruir a direção das mudanças semânticas no viés diacrônico.

O corpus de investigação é constituído por um conjunto de 73 enunciados com no que. Para o recorte do corpus, as decisões se pautaram em dois critérios: o tipo de texto e o estilo. Seguindo Kabatek (2005, p. 167), admito a correlação entre a tipologia textual e os mecanismos de junção, no sentido de que a temática, as finalidades comunicativas e as demais condições da produção dos textos predispõem o uso, a frequência e a distribuição das construções de junção, nas enunciações faladas e escritas. Como no que estabelece sentido temporal, estimei que textos predominantemente narrativos pudessem fornecer ocorrências. $\mathrm{O}$ segundo critério observado foi o estilo, apreciado em termos do nível 
de formalidade. As construções com no que são pouco prováveis em textos formais. Pesquisas em mudança, sobretudo em gramaticalização, das quais Rohdenburg (2008) é exemplar, apontam a correlação entre a emergência de construções novas e o grau menor de formalidade.

Assim, contemplando tipo de texto e estilo, para constituição do corpus, tomei textos predominantemente narrativos, de ambos os modos de enunciação. Do falado, foram duas amostras relativas ao interior paulista: banco de dados IBORUNA e banco de Relatos Pessoais. Essas amostras, coletadas sob os princípios da sociolinguística variacionista, encontram-se transcritas e disponíveis na base de dados da UNESP. Do escrito, foi constituída uma amostra de textos, todos extraídos da internet (ainda que vários deles tenham também circulação impressa, como é o caso dos noticiários e entrevistas), especificamente de blogs, noticiários gerais, entrevistas e depoimentos à justiça federal. ${ }^{2}$

Desenvolvo o texto em três partes. As duas primeiras tratam das posições teóricas sobre os temas maiores deste trabalho, junção e gramaticalização; e a terceira parte traz a análise dos dados. Em 3.1, discuto o estatuto conjuncional de no que, fundamentada nos parâmetros utilizados por Kortmann (1997) para aferir o grau de tipicidade dos juntores. Nessa seção, apresento uma hipótese explicativa acerca da reanálise sintagmática que deu lugar a no que. Em 3.2, ofereço uma classificação dos padrões de no que fundada no plano conceitual. Nessa seção, exploro tendências relacionadas à condução das mudanças de sentido. Em 3.3, mostro que a estruturação temática e informacional das construções com no que é decisiva para esclarecer a manobra argumentativa instaurada pelo juntor. Nas considerações finais, faço um balanço dos resultados e proponho para no que um cline de gramaticalidade baseado nas polissemias semântico-pragmáticas.

\section{Múltiplos aspectos da junção}

Diferentes abordagens, principalmente aquelas de base funcionalista e pragmático-textuais, têm acentuado que é múltipla a

\footnotetext{
${ }^{2}$ Agradeço ao aluno Diego Minucelli Garcia o trabalho cuidadoso na seleção dos textos, organização da amostra e posterior levantamento dos dados de no que, tarefa que realizou como parte das atividades de seu projeto de iniciação científica.
} 
natureza do elo existente entre os enunciados para a formação de um texto ou discurso e que, portanto, a descrição desse elo depende da consideração conjunta de fatores sintáticos, semânticos, pragmáticos e prosódicos (BALLY, 1965; HALLIDAY, 1985; MOESCHLER; REBOUL, 1994; RAIBLE, 2001; TABOADA, 2009; BEGUELIN, AVANZI; CORMINBOEUF, 2010, entre outros).

Um trabalho exemplar dessa perspectiva multidimensional é Raible (2001). Para o autor, a junção, dimensão universal da linguagem, pressupõe a mobilização de um conjunto de técnicas. A primeira se refere à criação de uma hierarquia sintática, em que os segmentos são articulados em arquiteturas mais e menos dependentes, que se situam nos polos difusos do contínuo que vai da agregação à integração. A segunda técnica se refere ao estabelecimento de relações de sentido, como tempo, causa, condição, modo, finalidade, concessão etc. O pareamento entre essas duas técnicas de junção, as mais relevantes segundo Raible, é tal que uma mesma relação de sentido encontra possibilidades de expressão em diferentes arquiteturas sintáticas. Dessa forma, fica descartada uma relação biunívoca entre forma e significado. A terceira técnica de junção, fortemente correlacionada à primeira, é o dinamismo comunicativo, que se refere às diferenças no relevo comunicativo conferido aos enunciados. A quarta técnica de Raible se refere à manutenção da referência, ou seja, às relações de correferência ${ }^{3}$ que são largamente dependentes do conhecimento de mundo e do conhecimento enciclopédico. A quinta técnica diz respeito ao papel que os gêneros ou tradições textuais têm para a escolha dos mecanismos de junção que compõem um texto. Em suma, na proposta de Raible, entram em pauta mecanismos sintáticosemânticos de construção de períodos e de construção da referência, além de mecanismos de ordem pragmático-textual, voltados ao fluxo de informação e aos gêneros textuais.

Outra proposta que também se funda na articulação entre os vários níveis de análise é o modelo sistêmico-funcional de Halliday (1985), que sustenta para a língua uma abordagem fortemente semântica com propósitos de análise textual e, nesse sentido, se compatibiliza com

\footnotetext{
${ }^{3}$ As abordagens de Raible (2001) e de Moeschler e Reboul (1994) se aproximam principalmente no que tange às técnicas do dinamismo comunicativo e das estratégias de correferenciação, que são abordadas por Moeschler e Reboul em termos de coerência temática e coerência referencial, respectivamente.
} 
Raible (2001). O eixo da gramática funcional (HALLIDAY, 1985) está na correlação entre as funções da linguagem e a estrutura da oração, em que a estrutura deve representar as funções distintas que a língua desempenha. Para o autor, toda oração é produto de três componentes semânticos simultaneamente codificados: ideacional, textual e interpessoal, do que resulta a consideração da oração como uma representação da experiência, uma mensagem e uma troca interativa, respectivamente.

Em Halliday (1985), tal como em Raible (2001), aspectos da junção se assentam no cruzamento entre informações dos eixos sintático e semântico. Para Halliday, a relação entre orações consiste em uma forma de modificação, conceito refinado pela consideração de dois parâmetros: tipo de interdependência (ou taxe) e tipo de relação de sentido. Dada a concepção sistêmica do modelo, fundado na escolha, há uma rede de opções para cada parâmetro. O tipo de taxe permite as opções de parataxe e hipotaxe, abordados em termos estruturais. Na parataxe, as orações têm o mesmo estatuto, enquanto, na hipotaxe, têm estatuto diferente, prevalecendo uma relação do tipo núcleo-modificadora. As opções de parataxe e hipotaxe se articulam com as relações de sentido que, por sua vez, se distribuem por outros dois eixos, denominados expansão e projeção, com seus respectivos conjuntos de opções.

Quanto aos sistemas responsáveis pela estruturação da oração enquanto mensagem, Halliday distingue o sistema de tematização, com articulação em tema/rema, e de informação, com articulação em dado/ novo. Embora exista nas línguas uma tendência à sobreposição entre esses sistemas, com a associação do tema ao dado e do rema ao novo, Halliday argumenta que tema/rema e dado/novo se definem a partir de critérios distintos. No âmbito da tematização, que diz respeito aos padrões de progressão, é possível reconhecer a articulação entre um tema, elemento que funciona como ponto de partida da mensagem, e um rema, que predica e desenvolve o tema. ${ }^{4}$ No âmbito da informação, que diz respeito à distribuição de informação, é possível reconhecer a articulação entre o dado, elemento recuperável no contexto prévio ou

\footnotetext{
${ }^{4}$ Segundo Halliday (1985), os juntores são itens inerentemente temáticos que indicam que o tema é, antes de tudo, um significado. É nesse sentido que parte do tema de qualquer oração que começa com se é precisamente sua relação condicional com a outra oração.
} 
relacionado à situação de fala, e o novo, não-recuperável ou contrastivo.

Sobre a dimensão temático-informacional, cuja relevância para a junção é admitida por Raible e por Halliday, a questão que se coloca é a de investigar até que ponto as articulações em tema/rema e em dado/ novo, que estruturam a oração, também estruturariam hierarquicamente a combinação entre orações. Uma proposta nessa via é aquela de Bally (1965), que estabelece três mecanismos de constituição de orações complexas que, nessa ordem, apresentam graus crescentes de dependência: coordenação, segmentação e soldadura. Bally concebe toda oração realizada como um ato de enunciação completo que se presta a uma caracterização funcional, sendo suscetível de bipartição em dois segmentos de importância comunicativa diferente: o tema e o propósito. O tema é definido como o ponto de partida ao qual é acrescido o propósito, que é o centro de interesse da comunicação. A sequência (tema)/propósito corresponde ao padrão habitual, sendo possível prever enunciações formadas apenas pelo propósito.

Para Bally, a articulação tema/propósito, que estrutura a oração simples, estrutura também a oração complexa. Em outras palavras, Bally defende que na combinação de orações, a segunda oração toma a primeira como tema e é no interior desse tema que ela deve ser interpretada como acrescentando a informação remática. Dos três mecanismos referidos por Bally, discuto a estrutura segmentada, da qual as construções com no que parecem se aproximar. Segundo Bally, as estruturas segmentadas resultam da condensação parcial de duas enunciações coordenadas, em que é possível distinguir as duas partes, o tema e o propósito. A segmentação se distingue da coordenação por apresentar uma interdependência maior entre as enunciações, no sentido de que cada vez mais uma é necessária à compreensão da outra. Há, portanto, uma diferença fundamental no valor sintático do primeiro segmento: ele é autônomo na coordenada e dependente na segmentada. Além disso, na segmentação, as enunciações são separadas por uma pausa breve e os contornos entoacionais são distintos, normalmente a oração propósito é mais saliente.

\section{Junção em mudança}

As construções com no que são analisadas aqui no quadro teóricometodológico da mudança gramatical, particularmente da mudança por 
gramaticalização, que é definida como um processo gradual em que construções menos gramaticais, quando usadas em contextos específicos, se tornam mais gramaticais, em função de um conjunto de alterações (HOPPER; TRAUGOTT, 1993; HEINE, 2003; HEINE; KUTEVA, 2007; TRAUGOTT, 2011). Tais alterações são abordadas por Heine e Kuteva (2007) em termos de quatro mecanismos: extensão contextual, dessemantização, descategorização e erosão. A singularidade da gramaticalização é assegurada, segundo os autores, pela interação entre esses mecanismos, que compõem uma ferramenta para identificação e descrição de casos de mudança.

A definição acima desfruta de um considerável consenso na literatura sobre o tema, dado o amplo reconhecimento de que os fatos de gramaticalização só ocorrem em contextos particulares. Aliás, contexto é uma noção chave em gramaticalização. Vários trabalhos (HEINE, 2002; DIEWALD, 2002; TRAUGOTT, 2012) têm oferecido análises sofisticadas sobre os tipos de contextos envolvidos na mudança, favorecendo, assim, a compreensão dos condicionamentos, das trajetórias unidirecionais da mudança e da gradualidade na fixação das categorias. Traugott (2012), por exemplo, defende que as inferências pragmáticas induzidas pelo contexto estrutural constituem condição necessária para a mudança (contextos bridging e critical, na terminologia de Heine e de Diewald, respectivamente).

Do universo da gramaticalização, neste trabalho, focalizo a ação do(s) contexto(s), tendo em vista a alteração nas fronteiras dos constituintes sentenciais e a constituição dos sentidos de no que. Quanto às alterações de significado, Kortmann (1997) traz evidências sobre os principais canais de derivação. $\mathrm{O}$ autor concebe quatro macrossistemas que comportam conjuntos de relações com elos de parentesco: modo, lugar, tempo e CCCC (causa, condição, concessão, contraste). Com base no estatuto cognitivo, Kortmann postula que lugar, modo e tempo são relações mais básicas (primitivas) e CCCC, especialmente concessão, são mais complexas. As trajetórias de mudança são condicionadas, segundo ele, pelas relações polissêmicas que se dão dentro e entre os macrossistemas, seguindo sempre em direção ao aumento de complexidade cognitiva.

O Esquema 1, produto da sistematização das mudanças investigadas por Kortmann, permite vislumbrar padrões de polissemia que subjazem às mudanças de significado. $\mathrm{O}$ esquema sugere que as 
afinidades semânticas são mais fracas entre lugar e tempo, tempo e modo, modo e CCCC, CCCC e lugar; que as afinidades semânticas são virtualmente ausentes entre lugar e modo; que todas as relações dão lugar a CCCC, mas não vice-versa; que lugar e modo dão lugar a tempo, mas não vice-versa; que tempo exibe as mais fortes afinidades semânticas com as relações CCCC, o que é sinalizado pela espessura da seta; e que tempo é alvo para lugar e modo.

Esquema 1 - Macroestrutura do universo semântico das relações oracionais (Kortmann, 1997)

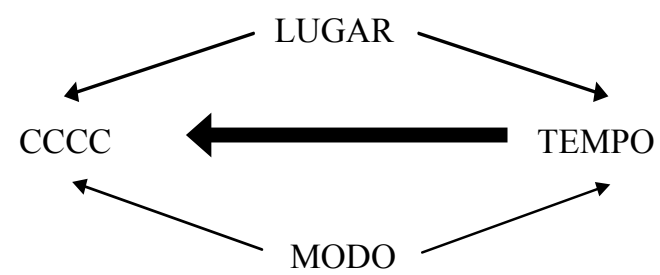

A partir desse esquema, é possível afirmar que o princípio que rege as mudanças no plano conceitual prevê que conceitos do domínio físico são usados como veículo para expressão de conceitos do domínio mental, numa clara demonstração de que a mudança se processa por meio de um percurso que segue do concreto para o abstrato. A direcionalidade concreto $>$ abstrato evidencia a face metafórica da mudança. Os processos metafóricos são tipicamente abordados em termos de mapeamentos ou projeções entre domínios, disparados pela analogia e pelas relações icônicas (HOPPER; TRAUGOTT, 1993, p. 78).

As projeções metafóricas podem predizer a direção dos processos de gramaticalização, mas sugerem que a emergência de uma categoria implica a substituição da anterior, sem dar conta dos possíveis estágios de sobreposição, que refletem a gradualidade da mudança. A esse respeito, Hopper; Traugott (1993, p. 80) e Hagège (2001, p. 1611) salientam a importância dos processos metonímicos, que acentuam a natureza contínua da transição entre significados. A metonímia está relacionada com a contiguidade em contextos linguísticos e pragmáticos. Mais especificamente, fatores contextuais, aliados a princípios lógicos e conversacionais (por exemplo, máximas griceanas), disparam inferências que sugerem um significado novo, em acréscimo ao significado fonte. 
Os significados novos, derivados do contexto, eventualmente podem ser semantizados, efetivando a mudança.

Nessa perspectiva, as mudanças de significado - semânticas e pragmáticas - nunca são arbitrárias, mas encontram motivação nos mecanismos de ordem metafórica e metonímica que, embora atuem em planos diferentes, já que a primeira é paradigmática e analógica e a segunda, sintagmática e associativa, complementam-se na condução da complexa operação entre significados, como enfatiza Hagège (2001):

On peut dire, en conclusion de tout ce qu'on vient de voir, que la place prise dans la grammaticalisation par les processus de transfert métaphorique n'exclut pas les processus métonymiques. C'est le recours à une interprétation mettant en évidence une action conjuguée de l'un et de l'autre qui paraît le mieux rendre compte de cette opération complexe. (HAGĖGE, 2001, p. 1612)

\section{As construções com no que: forma e significado}

\subsection{Estatuto conjuncional de no que}

Partindo de propriedades morfológicas e semânticas, Kortmann (1997, p. 71-73) elenca uma série de critérios que permitem avaliar o caráter conjuncional mais e menos prototípico dos juntores, o que garante um tratamento mais sistemático para essa classe de palavras, que é heterogênea em essência. $O$ autor enumera, entre outros, o fato de os juntores típicos não serem categorias flexionáveis, não cumprirem função sintática e não apresentarem mobilidade posicional dentro da oração de que fazem parte.

Conforme os dados em análise, no que não apresenta flexão, não desempenha qualquer função sintática e situa-se em geral no início da

\footnotetext{
${ }^{5}$ Versão sugerida: Em conclusão a tudo que vimos, podemos dizer que na gramaticalização o lugar ocupado pelo processo de transferência metafórica não exclui os processos metonímicos. Uma interpretação que coloca em evidência uma ação conjugada de um e de outro parece ser a melhor forma de explicar essa operação complexa (HAGÈGE, 2001, p. 1612).
} 
primeira oração de uma construção estritamente binária, hipotática, do tipo [no que $\mathrm{O}_{1}, \mathrm{O}_{2}$ ], em que $\mathrm{O}_{1}$ é uma oração simples e $\mathrm{O}_{2}$, uma oração simples ou um complexo oracional, como mostram, respectivamente, (03) e (04). ${ }^{6} \mathrm{Em}(03), \mathrm{O}_{1}$ e $\mathrm{O}_{2}$ são orações simples, em (04), $\mathrm{O}_{2}$ é realizada por uma sequência de três orações. Há no corpus ocorrências que comportam material interveniente a $\mathrm{O}_{1}$ e $\mathrm{O}_{2}$, como em (05).

(03) aí eles saíram pra pescar de noite, né? aí... no que eles tava pescando lá eles viram uma luz assim do outro lado do rio. (Iboruna/ AC-015)

(04) Quando ele teve a oportunidade, enfiou o carro inteiro no espaço de um palmo, sendo duas rodas no asfalto e outras duas na calçada. No que ele subiu na guia, ele bateu a roda dianteira dele na minha traseira e decolou, caindo em cima da minha cabeça. (tazio.uol. com.br)

(05) A lei da gravidade foi determinante mais uma vez. Não a conhecia até esse dia, pelo menos nunca tinha me dado conta de sua eficiência. No que coloquei o pé no ar, sem apoio algum e com o corpo em posição para o salto, ligeiramente inclinado para frente, a queda foi inevitável e muito rápida. (romeuparis.blogspot.com.br)

Quanto ao estatuto dos juntores complexos, principalmente daqueles que envolvem nome genérico seguido de complementizador ou relativizador, Kortmann (1997, p. 73) postula que essas expressões perifrásticas precisam cumprir pelo menos um dos seguintes critérios: (a) devem exibir uma fusão mínima; (b) devem ter perdido pelo menos algumas de suas propriedades originais; e, (c) devem ter pelo menos uma interpretação que não é totalmente recuperável a partir do significado das partes (condição de não-composicionalidade).

Avalio o critério (a), fusão mínima, do ponto de vista morfológico, em termos da invariabilidade na ordem dos elementos da construção e da impossibilidade de inserção de material entre no e que. Aplicado às

\footnotetext{
${ }^{6}$ Para apresentação dos exemplos, adoto a seguinte convenção: negrito para o juntor no que e itálico para toda a construção. No final, entre parênteses, informo a procedência do dado.
} 
ocorrências de no que, esse critério se aplica a 100\% dos casos, reforçando a noção de unidade formal. Para exame do critério (b), que diz respeito às possíveis perdas sofridas pela construção fonte, avalio traços de forma e de sentido da construção que julgo estar na origem da derivação de no que. Sem a pretensão de esgotar a questão, a hipótese explicativa que assumo aqui reside nas mudanças experimentadas pela expressão no momento em que, na qual o nome genérico temporal momento, inserido no contexto de sintagma preposicional, teria seu significado complementado por uma oração subordinada. Embora a expressão ainda apresente contextos de uso no português contemporâneo, ${ }^{7}$ no corpus examinado, só há ocorrências já com apagamento da segunda preposição (isto é, no momento que).

A derivação a partir de no momento em que encontra respaldo nas ponderações de Hopper; Traugott (1993, p. 65) sobre as motivações para a gramaticalização, que devem ser buscadas nos contextos de interação. Os autores defendem a existência de forças que levam à simplificação da fala, com reduções e compactações, e de forças que levam a novas maneiras de dizer, mais criativas e expressivas. Desse ponto de vista, o uso conjuncional de no que seria fruto da competição entre motivações: redução do sinal de fala (descategorização da construção e perda de material), por um lado, e criatividade (um juntor novo, com suas especificidades), por outro. A hipótese se fortalece ainda em certas evidências encontradas no corpus: (i) todas as ocorrências de no que codificam tempo e admitem paráfrase com no momento que; (ii) há casos em que o enunciador hesita na escolha entre no que e no momento que, conforme (06); e, (iii) a presença de no momento que no contexto precedente favorece o emprego de no que no contexto subsequente, conforme (07).

(06) daí eu peguei e falei - "óh eu vou num bar ali comprar um maço de cigarro" - eu fui lá... e no que eu/no momento que eu fui no no... lá no bar na lanchonete comprar um cigarro... eu voltei no que eu voltei já num tava lá mais. (Iboruna/AC-031)

\footnotetext{
${ }^{7}$ Uma busca realizada no 'Corpus do Português' (corpusdoportugues.org), que reúne dados do português brasileiro e do português europeu, de diferentes gêneros, resultou em 589 ocorrências de no momento em que como, por exemplo: No momento em que Afonso chegava-se para tentar a subida, o pinheiro estremecera violentamente abalado (501/18:Alencar/:Til).
} 
(07) No momento que eu estava pulando o muro eu vi o Domingos levantando, pelos pés da cama, porque dá pra ver bem o quarto da janela deles. Vi ele levantando e colocando um calção, ele estava só de cueca. E nisso ele saiu para fora e no que eu chego na lateral ele grita 'ela jogou a nenê, ela jogou a nenê'. Tentei subir por ali e não consegui, e no que eu volto pra gritar pra pedir uma escada, o morador do apartamento do meio grita que em seu telhado estava a criança. (jornalsemario.com.br)

À luz dessa interpretação dos fatos e visando a responder ao critério (b), é possível argumentar em favor da perda de características originais: queda da preposição em; queda do núcleo nominal momento, que representa a dissolução do sintagma; e descategorização do determinante artigo, que perde a possibilidade flexional de número. Em contrapartida, dada sua natureza pronominal, o artigo assimila a semântica temporal genérica do nome, enquanto que é reanalisado como parte componente da perífrase conjuncional, em analogia às tantas perífrases conjuncionais do tipo $x+q u e$. O esquema, a seguir, é representativo desse percurso:

Esquema 2 - Reanálise sintagmática de no que

$$
[\text { no (momento) }][(\mathrm{em}) \text { que }]>[\text { no] [que }]>\text { [no que }]
$$

Acrescente-se que, da perspectiva do sentido, a semântica temporal, retida no artigo, ganha em opacidade, passando a coexistir com leituras causal e condicional (Seção 3.2), comprovando a possibilidade de interpretações independentes da significação das partes e atendendo, assim, à exigência do critério (c).

\subsection{Os padrões de uso de no que}

Todas as ocorrências de no que veiculam sentido temporal. Entretanto, algumas delas admitem também interpretações em termos de causalidade e de condição, o que indicia para a construção um considerável grau de não-discretude conceitual e permite distinguir três padrões de uso de no que, que denomino: temporal, tempo-causal e tempo-condicional, conforme, respectivamente, os exemplos de (08) a (10). Diante desse cenário, as questões que se colocam referem-se ao 
estatuto primário ou secundário ${ }^{8}$ das interpretações causal e condicional e aos possíveis trânsitos de significado a partir do domínio de tempo.

Temporal (T)

(08) o moleque tava correndo atrás dele mesmo né?... só que eu achei que era mentira, né? que ele passou correndo e eu comecei dar risada, aí o moleque falou assim "então olha pra trás que você vai ver" $-\ldots$ no que eu olhei pra trás assim tinha dois moleque descendo de bicicleta na avenida, um com um facão na mão. (Iboruna/AC-015)

Tempo-causal (TCA)

(09) aquele dia ele ia indo tava chuviscando e teve um acidente do outro lado, e ele quis frear do lado de cá... e no que ele freou ele rodou. (Iboruna/AC-122)

Tempo-condicional (TCO)

(10) Canjica, eu comi. Ah! Comida mais rala, você comer uma sopa, tudo que é comida mais rala, é bom pro leite, porque aquilo aumenta... eu sei, porque quando eu quero que o leite aumenta mais, eu faço canjica e tomo... aí no que eu tomo a canjica, já parece que... é uma coisa que rende mesmo. (cielo.br)

A Tabela 1 mostra que esses padrões apresentam frequências variáveis no corpus. O temporal é o mais frequente, correspondendo a $73 \%$ do total das ocorrências. No padrão T, as orações introduzidas por no que acrescentam uma circunstância temporal que serve de moldura para o evento descrito na oração seguinte. As ocorrências em (11) e (12), além de (08), sugerem, contudo, que há mais de uma nuança temporal envolvida nas construções de no que. Os três exemplos têm em comum a relação temporal entre os eventos codificados nas orações, mas há diferenças: (08) comporta o traço simultaneidade; (11), anterioridade; e, (12), posterioridade.

\footnotetext{
${ }^{8}$ À maneira de Kortmann (1997, p. 94), assumo que o critério mais decisivo para distinção entre os significados primário e secundário é a exigência de um contexto especial: os significados secundários, diferentemente dos primários, são sustentados por traços contextuais.
} 
Tabela 1 - Frequência dos padrões de no que

\begin{tabular}{|l|c|}
\hline PADRÕES DE NO QUE & FREQUÊNCIA \\
\hline Tempo (T) & $53 / 73(73 \%)$ \\
\hline Tempo/Causa (TCA) & $16 / 73(22 \%)$ \\
\hline Tempo/Condição (TCO) & $04 / 73(05 \%)$ \\
\hline
\end{tabular}

(11) meu pai conta... que ele iscou com uma... eu nem sei como que chama a isca que ele põe no peixe... espadinha (se eu não tô enganada) parece uma enguia... ele iscou... e jogou... e ele joga... BEM longe... e vai deixando a isca:: correr... só que no que ele jogou passou um pássaro... (Iboruna/AC-086)

(12) Aponta uma Van "Mercadão de Madureira". Metade do trajeto que preciso. Perfeito! No que entro, já está um pivete sentado na janela, do último banco, falando ao celular. (deviacaobusao.blogspot)

As relações temporais podem ser múltiplas e uma descrição mais refinada acerca do tipo de relação temporal pode favorecer a compreensão da rede interpretativa polissêmica colocada em jogo por no que. Para tanto, analiso os dados de no que à luz da proposta de Kortmann (1997, p. 84-85), entendendo tempo como um macrossistema de relações semântico-cognitivas, que se desdobra em relações mais específicas. Com frequentes sobreposições, tais relações revelam a existência de diferentes graus de afinidade semântica. ${ }^{9}$ Das sete relações temporais reconhecidas por Kortmann, no que está correlacionado a cinco, conforme os exemplares abaixo:

- Simultaneidade com sobreposição (Siover): $p$ se sobrepõe a $q$

\footnotetext{
${ }^{9}$ Os tipos temporais não são discretos. Internamente à rede temporal, como argumenta Kortmann (1997, p. 182), as relações podem mostrar maior ou menor afinidade semântica. Essa fluidez semântica inerente a tempo ficou clara na análise das ocorrências de no que. Há casos que podem se enquadrar em mais de um tipo como, por exemplo, (17), que transita pela contingência e pela anterioridade imediata.
} 
(13) eu fiquei segurando o portão assim... eu não aguentava segurar mais ele... aí ele chegou... no que ele chegou ele tava meio bêbado, né? tava meio cambaleando... (Iboruna/AC-015)

- Simultaneidade com duração (Sidur): $p$ abre um intervalo temporal em que todo ou parte de $q$ é verdadeiro

(14) Aconteceu de meu celular tocar e como não gosto de atender meu celular com todo mundo me olhando e fazendo silêncio, ouvindo minha conversa, saí pela porta e estou na calçada enquanto falo. No que eu volto, noto pela porta, que é de vidro, que aquele gordo filho de satã está fechando a porta por dentro. (blogdocatito.wordpress.com)

- Anterioridade imediata (Imante): $p$ imediatamente precede $q$

(15) É manhã na cidade do Porto e, no que chego, chove, turvando a visão diante de uma paisagem distinta. (cronicasderobertolima.blogspot. com.br)

- Posterioridade (Post): $p$ segue $q$ no tempo

(16) Eu até pensei que tivesse saído o meu comentário no blog que falava a respeito do assunto, mas até às 18:00 hs. de ontem, não havia saído. Depois não tive mais tempo de verificar. Eu tinha voltado para ler um outro post e também já ia deixar outro comentário. Porém, no que volto, um colega havia deixado um recado que o cara não publicava todos os comentários. (blogdosakamoto.blogsfera.uol.com.br)

- Contingência (Conting): $p$ sempre que $q$ (tempo indefinido, habitual)

(17) Entrevistador: Como é o processo de criação dos seus personagens?

Entrevistado: No que começo a pensar na trama, os personagens vão vindo à minha imaginação. Tenho muita facilidade em criá-los. (nomundodosfamosos.zip.net) 
Apesar da variedade de sentidos temporais codificados pelas construções com no que, as frequências mostradas na Tabela 2, a seguir, sugerem que a relação temporal por excelência é anterioridade imediata (Imante), que equivale a 77\% (56/73) dos casos de no que. Mas a tabela sugere também possíveis especializações, fundamentais para delinear o funcionamento dos padrões de no que: (i) o padrão $\mathrm{T}$ é o que codifica o número maior de tipos temporais, exceto contingência; (ii) o padrão TCA se sustenta essencialmente na anterioridade imediata; (iii) o padrão TCO é o único que codifica contingência; (iv) o padrão T é o único que codifica posterioridade.

Tabela 2 - Padrões de no que e tipo de relação temporal codificado

\begin{tabular}{|l|l|l|l|l|l|}
\cline { 2 - 6 } \multicolumn{1}{c|}{} & \multicolumn{5}{c|}{ TIPO DE RELAÇÃO TEMPORAL } \\
\cline { 2 - 6 } \multicolumn{1}{c|}{} & Sidur & Siover & Imante & Post & Conting \\
\hline T & $03 / 53(06 \%)$ & $01 / 53(02 \%)$ & $41 / 53(77 \%)$ & $08 / 53(15 \%)$ & - \\
\hline TCA & $01 / 16(06 \%)$ & - & $15 / 16(94 \%)$ & - & - \\
\hline TCO & - & - & - & - & $04 / 04(100 \%)$ \\
\hline TOTAL & $04 / 73(05 \%)$ & $01 / 73(02 \%)$ & $56 / 73(77 \%)$ & $08 / 73(11 \%)$ & $04 / 73(05 \%)$ \\
\hline
\end{tabular}

O padrão TCA reúne ocorrências que, além do sentido temporal, são suscetíveis de uma leitura causal, em que o evento precedente é relevante para a interpretação do evento seguinte, em termos de causa e efeito, tal como é o caso de (09), (18) e (19), que admitem as paráfrases: porque freou, rodou; porque viu os caras, procurou um objeto para se defender; porque sentiu uma mão agarrar o pé, desferiu um coice.

(18) eu fui lá fora e nisso chegaram três caras... e... no que eu vi os três caras eu... procurei um pedaço de pau... (NEP/n2, A1)

(19) Pedro, tonto de pavor, tentou agarrar o amigo e, na escuridão acabou cravando as unhas, das mãos geladas em seu tornozelo. Antonio nem teve tempo de pensar, foi no reflexo. No que sentiu a mão nervosa tentando agarrar seu pé, desferiu um coice de arrancar até defunto da cova. (dericarterror/blogspot)

A sucessão temporal contribui para alimentar a causalidade. $\mathrm{O}$ trânsito metafórico tempo >causa já foi atestado em inúmeros fenômenos 
de gramaticalização de juntores (TRAUGOTT; KÖNIG, 1991; KORTMANN, 1997; RAIBLE, 2001). Aliás, segundo o estudo tipológico de Kortmann, mencionado anteriormente, a categoria de tempo é a fonte mais produtiva para emergência dos significados conjuncionais causais, condicionais e contrastivos. No canal tempo $>$ causa, que subjaz ao padrão TCA, a sucessão temporal entre os eventos no mundo se traduz, no plano linguístico, na ordem das orações, do que resulta uma ordem icônica, pautada na convergência entre mundo e linguagem. Essa ordem icônica habilita interpretar o que vem antes como causa e o que vem depois como efeito. Os dados da Tabela 2 referentes à TCA reforçam esse ponto de vista, pois, em $94 \%$ dos casos, a oração encabeçada por no que codifica anterioridade imediata, reinterpretada como causa.

A sucessão temporal icônica habilita, mas não é suficiente para garantir a leitura causal. Só o contexto pragmático, incluindo o conhecimento e as crenças acerca do mundo, é que tornam plausível a leitura causal. Em outras palavras, a relação de tempo por si só não basta para a emergência de causa, como comprovam as ocorrências do Padrão T, que não têm acepção causal. Portanto, nas ocorrências do padrão TCA, o sentido de causa é secundário, sustentando-se tanto no contexto linguístico, especificamente na ordem das orações, na semântica verbal (evento, ação) e no tipo de relação temporal, como no contexto pragmático, nos esquemas enunciativos que legitimam no mundo a implicação entre uma causa e um efeito. Esses resultados corroboram aqueles de Ziv (1993) e Paiva e Braga (2010), sobre construções causais justapostas e coordenadas com $e$.

O padrão TCO reúne as ocorrências que, além do sentido temporal, permitem uma leitura condicional, conforme $(20)^{10} \mathrm{e}(21)$. Nesse padrão, é o tempo habitual ou contingente que habilita a leitura condicional, como indica a Tabela 02 . A contingência opera de maneira diferenciada no eixo do tempo, sinalizando uma habitualidade, uma eventualidade temporal. Trata-se, portanto, de um tempo "indefinido" se comparado aos demais temporais. O conteúdo de (20) repousa na argumentação da enunciadora em favor da implicação causal que ela acredita existir entre o consumo de canjica e a produção de leite. Observa-se, nesse contexto, que o enunciado no que eu tomo a canjica não expressa propriamente

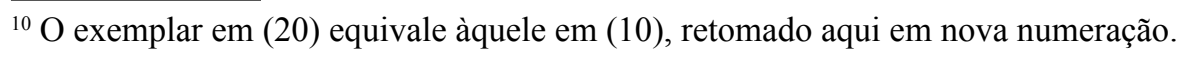


um evento realizado, mas um evento que, sempre que repetido, vai ter por consequência o aumento de leite (é uma coisa que rende mesmo). Atente-se ainda ao contexto anterior a no que, em que o enunciado com quando já transita pela condicionalidade (quando/sempre que/se eu quero que o leite aumenta mais, eu faço canjica e tomo). Também, em (21), de maneira similar, o que está em relevo é a iteratividade do evento e seu desdobramento. Nesses termos, o sentido condicional é secundário, derivado de traços do contexto (polissemia semântico-pragmática).

(20) Canjica, eu comi. Ah! Comida mais rala, você comer uma sopa, tudo que é comida mais rala, é bom pro leite, porque aquilo aumenta... eu sei, porque quando eu quero que o leite aumenta mais, eu faço canjica e tomo... aí no que eu tomo a canjica, já parece que... é uma coisa que rende mesmo. (cielo.br)

(21) Antes de fazer meu primeiro assalto, treinei um mês em casa. Ensaiei até as frases para dizer para o caixa. A mão suava só de me imaginar de frente para o vigilante. Agora, não: é igual pular de bungee-jump. Quando estou de frente para o banco, dá aquele frio na barriga. No que eu entro, a coisa vai sozinha. Faço cinco caixas em quarenta segundos. Quando a polícia chega, já caí no mundão - e aí é só felicidade. (veja.abril.com.br)

Nas ocorrências de TCO também é legítimo interpretar a relação temporal introduzida por no que como uma instância da anterioridade imediata, ainda que menos evidente diante da iteratividade traduzida pelos enunciados. Os dados sugerem, assim, uma flutuação semântica entre anterioridade e contingência. São várias as referências, na literatura sobre junção e mudança, acerca da correlação entre os domínios de tempo e de condição, em que certas nuanças temporais alimentam a relação de condição. Destaco Jiménez (1990):

En cierto modo, la simultaneidad o sucesión (más o menos inmediata) temporal constituye un tipo de concomitancia, por lo que fácilmente se presta también, y no sólo en nuestra lengua, a servir de cauce para la expresión de la relación condicional; dos acciones que tienen lugar al mismo tiempo o se suceden la una a la otra acaban 
concibiéndose a menudo como ligadas por una clase de dependencia más estrecha que la puramente cronológica. No extraña, pues, que entre las conjunciones condicionales se incluyan términos y expresiones temporales: cuando, en cuanto, mientras (que), siempre que, siempre y cuando, hasta que, etc. (JIMÉNEZ, 1990, p. 98). ${ }^{11}$

A Tabela 3, na qual apresento as frequências da apuração da categoria modo-temporal do verbo das orações núcleo e modificadora, traz elementos que reforçam as descrições dos padrões de no que apresentadas acima. A legenda que acompanha a Tabela contém as siglas $\mathrm{P}, \mathrm{I}, \mathrm{F}, \mathrm{H}$ e E para, respectivamente, perfeito, imperfeito, futuro, presente histórico (morfologia de presente, valor de passado) e presente. Nos pares que aparecem no eixo horizontal da tabela (PP, PI, IP, II etc), a primeira sigla indica o tempo da primeira oração da construção e a segunda, o tempo da segunda oração.

Tabela 3 - Correlação modo-temporal das orações articuladas por no que

\begin{tabular}{|c|c|c|c|c|c|c|c|c|}
\hline & \multicolumn{8}{|c|}{ CORRELAÇÃO MODO-TEMPORAL } \\
\hline & PP & PI & IP & II & $\mathrm{HH}$ & HP & $\mathrm{HI}$ & EE \\
\hline $\mathrm{T}$ & $\begin{array}{l}18 / 53 \\
(34 \%)\end{array}$ & $\begin{array}{l}04 / 53 \\
(7,5 \%)\end{array}$ & $\begin{array}{l}01 / 53 \\
(02 \%)\end{array}$ & $\begin{array}{l}01 / 53 \\
(02 \%)\end{array}$ & $\begin{array}{l}22 / 53 \\
(41,5 \%)\end{array}$ & $\begin{array}{l}04 / 53 \\
(7,5 \%)\end{array}$ & $\begin{array}{l}03 / 53 \\
(5,5 \%)\end{array}$ & - \\
\hline TCA & $\begin{array}{l}13 / 16 \\
(82 \%)\end{array}$ & $\begin{array}{l}02 / 16 \\
(12 \%)\end{array}$ & - & - & $\begin{array}{l}01 / 16 \\
(06 \%)\end{array}$ & - & - & - \\
\hline TCO & - & - & - & - & - & - & - & $\begin{array}{l}04 / 04 \\
(100 \%)\end{array}$ \\
\hline TOTAL & $\begin{array}{l}31 / 73 \\
(42,5 \%)\end{array}$ & $\begin{array}{l}06 / 73 \\
(08 \%)\end{array}$ & $\begin{array}{l}01 / 73 \\
(1,5 \%)\end{array}$ & $\begin{array}{l}01 / 73 \\
(1,5 \%)\end{array}$ & \begin{tabular}{|l}
$23 / 73$ \\
$(31,5 \%)$
\end{tabular} & $\begin{array}{l}04 / 73 \\
(5,5 \%)\end{array}$ & $\begin{array}{l}03 / 73 \\
(04 \%)\end{array}$ & $\begin{array}{l}04 / 73 \\
(5,5 \%)\end{array}$ \\
\hline
\end{tabular}

Legenda: $\mathrm{P}=$ Perfeito; I = Imperfeito;

$\mathrm{E}=$ Presente; $\mathrm{H}=$ Presente histórico

\footnotetext{
${ }^{11}$ Versão sugerida: De certo modo, a simultaneidade ou sucessão temporal (mais ou menos imediata) constitui um tipo de concomitância que facilmente funciona, e não só em nossa língua, como canal para a expressão da relação condicional; duas ações que têm lugar ao mesmo tempo ou que se sucedem são concebidas como estando ligadas por uma forma de dependência mais estreita do que a puramente cronológica. Não é estranho, portanto, que entre as conjunções condicionais incluam-se termos e expressões temporais: cuando, en cuanto, mientras (que), siempre que, siempre y cuando, hasta que etc. (JIMÉNEZ, 1990, p. 98)
} 
Os números mostram que as construções com no que se realizam com formas modais de indicativo e preferencialmente com tempo passado. Além disso, reforçam que os padrões T e TCA estão fortemente correlacionados à codificação de passado (perfeito, imperfeito e presente histórico), colocando em evidência o aspecto realizado, ao passo que o padrão TCO está correlacionado à codificação de presente, colocando em evidência o aspecto habitual (contingente), que enfraquece o vínculo causal e fortalece o condicional. Trata-se, em outras palavras, de traços morfossintáticos importantes para sustentação dos sentidos.

A polissemia semântico-pragmática das construções com no que, tal como é discutida aqui, corrobora as pesquisas que evidenciam o trânsito metafórico entre tempo/causa e o trânsito metafórico entre tempo/condição, fortalecendo, assim, tendências em mudança semântica observadas em diversas línguas (KORTMANN, 1997; COUPERKUHLEN; KORTMANN, 2000; MOSCOW, 2001), em perspectiva sincrônica e diacrônica. O Esquema 3 resume o trânsito de sentidos que vem ocorrendo na constituição de no que como juntor e confirma expectativas que direcionam para um aumento de abstratização, já que as relações de causa e de condição, no âmbito de CCCC, são consideradas mais abstratas e cognitivamente mais complexas.

Esquema 3 - Esboço geral do trânsito de sentidos de no que

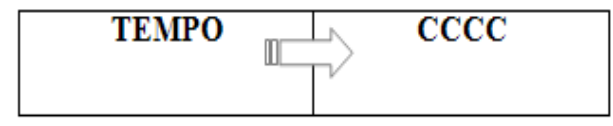

$$
\begin{aligned}
& \text { aumento de abstratização } \\
& \text { aumento de complexidade cognitvia }
\end{aligned}
$$

Esses resultados corroboram ainda o postulado de Traugott; Dasher (2002), segundo o qual, na mudança gramatical, os significados novos tendem a ganhar em subjetividade, no sentido de que se tornam cada vez mais baseados na crença/atitude do falante com respeito ao que é dito. Para os autores, conectores causais e condicionais, que têm natureza derivada, são frequentemente usados para sinalizar a perspectiva do falante/escrevente sobre o modo como os eventos se relacionam. 


\subsection{Articulação temático-informacional e argumentação}

Nesta seção, examino as construções com no que à luz do parâmetro dinamismo comunicativo, considerando, para tanto, os sistemas de estruturação temático e informacional, tal como foram referidos nos trabalhos de Bally (1965), Halliday (1985) e Raible (2001), discutidos em seção anterior. $\mathrm{O}$ interesse maior está na avaliação da tese - explícita em Bally e sugestiva em Halliday - de que os níveis de organização temático e informacional excedem o nível da oração simples, sendo cruciais para a estruturação dos enunciados complexos. A consideração dessa tese é que licencia a análise de no que em termos de foco ou dramatização.

Segundo Bally (1965), a articulação em tema e propósito estrutura a combinação de orações, num procedimento altamente coesivo. $\mathrm{Na}$ combinação por segmentação, as orações estão relacionadas de tal forma que a segunda toma a primeira como tema, e é no interior desse tema que ela deve ser interpretada como acrescentando ao discurso a informação central para o interesse da comunicação. Aplicando as noções de tema e propósito às construções com no que, é possível obter leituras em dois níveis: no primeiro nível, $\mathrm{O}_{1}$ e $\mathrm{O}_{2}$ são enunciações distintas, passíveis de análise em tema e propósito, mas mostram relações de dependência estrutural e semântica. Os traços de dependência foram avaliados nos mecanismos de continuidade referencial ${ }^{12}$ e de identidade temporal das orações (Tabela 3). No segundo nível, $\mathrm{O}_{1}$ e $\mathrm{O}_{2}$ são enunciações solidárias que funcionam, respectivamente, como tema e propósito de uma construção maior, prevalecendo o padrão habitual em que o tema é seguido pelo propósito. Nessa perspectiva, na construção com no que, $\mathrm{O}_{2}$ é o segmento comunicativamente mais saliente. O Esquema 4, a seguir, baseado na ocorrência em (01) retomada aqui em nova numeração, é representativo dessa análise em dois níveis:

(22) ele tava indo embora no que ele saiu da cidade, o carro quebrou. (Iboruna/AC-075)

\footnotetext{
${ }^{12}$ Investiguei a correferência dos sujeitos das orações. O resultado apontou correferência positiva (partilhamento do mesmo referente para ambos os sujeitos) em $41 \%$ dos casos (por exemplo, no que ele chegou, ele tava meio bêbado). No entanto, há outro tipo de relação referencial, mais relevante e mais indiciário de dependência, que será discutido no final desta seção (3.3).
} 
Esquema 4 - Combinação com no que e articulação em tema e propósito

\begin{tabular}{|c|c|c|c|}
\hline \multicolumn{2}{|c|}{$\mathbf{O}_{1}$} & \multicolumn{2}{c|}{$\mathbf{O}_{2}$} \\
\hline \multicolumn{2}{|c|}{ no que ele saiu da cidade } & \multicolumn{2}{c|}{ o carro quebrou } \\
\hline no que ele ${ }^{13}$ & saiu da cidade & o carro & quebrou \\
\hline tema & propósito & tema & propósito \\
\hline \multicolumn{2}{|c|}{ TEMA } & \multicolumn{2}{c|}{ PROPÓSITO } \\
\hline
\end{tabular}

Para aferição do estatuto informacional de $\mathrm{O}_{1}$ e $\mathrm{O}_{2}$, lancei mão das categorias dado e novo, às quais acrescentei a categoria inferível. $\mathrm{O}$ critério para definição das categorias é essencialmente contextual, à maneira de Halliday (1985), mas com ressalvas e adaptações. As opções de informação, dado e novo, são abordadas por Halliday no domínio das unidades entoacionais ou unidades informativas, que podem ou não coincidir com a oração, ao passo que, neste trabalho, a unidade de análise é a oração. Além disso, incluí a categoria inferível, contemplada no trabalho de Prince (1981), que defende uma abordagem textual.

A classificação dado se aplicou às orações que trazem conteúdos já mencionados explicitamente no contexto prévio, como é o caso de $\mathrm{O}_{1}$, em (23), em que ele jogou é informação contida no enunciado imediatamente anterior. A classificação novo se aplicou às orações que trazem informação mencionada pela primeira vez, como na $\mathrm{O}_{2}$, em (23). A classificação inferível se aplicou às orações que trazem informações dedutíveis a partir de diversos tipos de associação como, por exemplo, $\mathrm{O}_{1}$, em (24), em que pegar a comanda traz uma informação inferível a partir da consideração do contexto linguístico anterior (comprar uma cerveja no bar) e do contexto cognitivo (modelos do mundo, particularmente sobre os procedimentos para compra de bebida num bar).

(23) aí ele chegou e jogou [no que ele jogou $] \mathrm{O}_{1}$ [caiu em cima da minha $m \tilde{a} o] \mathrm{O}_{2} \ldots$ minha mão ficou preta. (Iboruna/AC-066)

${ }^{13}$ Halliday (1985) prevê múltiplos temas (de ordem ideacional, textual e modal) para uma mesma oração. No exemplo em questão, no que é tema textual e ele, tema ideacional. 
(24) Por volta das $2 \mathrm{~h} 45 \mathrm{~min}$, resolvi ir ao banheiro. Na volta, parei para comprar uma cerveja no bar. [No que peguei a comanda] $\mathrm{O}_{1}$, [vi aquele mar de gente saindo $\mathrm{OO}_{2}$. [zerohora.clicrbs.com.br]

A Tabela 4 relaciona os padrões de no que à ordem das orações e ao estatuto informacional. As frequências sinalizam que o estatuto informacional de $\mathrm{O}_{1}$ é variável (dado, inferível ou novo), enquanto o de $\mathrm{O}_{2}$ é sempre novo. Contudo, $\mathrm{O}_{1}$ tende a codificar com mais frequência informação dada e inferível, respectivamente, em $40 \%$ e $44 \%$ das ocorrências. Como a anteposição de no que é quase categórica nos dados ${ }^{14}$ é possível generalizar afirmando que as orações encabeçadas por no que se especializam na codificação de informação já conhecida ou inferível, como indicam as hachuras. Assim, a informação nova, mais dinâmica e essencial comunicativamente (RAIBLE, 2001), é codificada por excelência em $\mathrm{O}_{2}$. Esse resultado está em conformidade com o princípio funcional de distribuição de informação segundo o qual a sequência dado/ novo é não-marcada para o discurso coerente.

Tabela 4 - Padrões de no que, ordem e estatuto informacional

\begin{tabular}{|l|c|c|c|c|}
\cline { 3 - 5 } \multicolumn{2}{c|}{} & \multicolumn{3}{c|}{ ESTATUTO INFORMACIONAL } \\
\cline { 3 - 5 } \multicolumn{2}{c|}{} & dado/novo & inferivel/novo & novo/novo \\
\hline \multirow{2}{*}{$\mathrm{T}$} & anteposta & $17 / 53(32 \%)$ & $25 / 53(47 \%)$ & $10 / 53(19 \%)$ \\
\cline { 2 - 5 } & posposta & - & - & $01 / 53(02 \%)$ \\
\hline \multirow{2}{*}{ TCA } & anteposta & $09 / 16(56 \%)$ & $06 / 16(38 \%)$ & $01 / 16(06 \%)$ \\
\cline { 2 - 5 } & posposta & - & - & - \\
\hline \multirow{2}{*}{ TCO } & anteposta & $03 / 04(75 \%)$ & $01 / 04(25 \%)$ & - \\
\cline { 2 - 5 } & posposta & - & - & - \\
\hline TOTAL & & $29 / 73(40 \%)$ & $32 / 73(44 \%)$ & $12 / 73(16 \%)$ \\
\hline
\end{tabular}

\footnotetext{
${ }^{14} \mathrm{~A}$ única ocorrência verificada no corpus em que a oração introduzida por no que vem posposta é: Um súbito desespero dominou-o, no que sentiu gotas de suor escorrerem pela testa. (ethernyt.com.br)
} 
A análise do estatuto informacional mostrou também que as construções com no que são fortemente dependentes do contexto prévio. A oração introduzida por no que se sustenta numa informação conhecida e, para tanto, retoma por anáfora parte do conteúdo mencionado anteriormente. Essa retomada se dá de modo frequente pela repetição explícita, conforme as expressões grifadas em (25) a (27), ou pela inferenciação, conforme (28) a (30), do que resultam as classificações da Tabela 4, nas categorias dado e inferivel. A anáfora, entendida como uma estratégia de coesão e, ao mesmo tempo, como técnica de junção (RAIBLE, 2001), é constitutiva das relações estabelecidas por no que, que se concretizam em um duplo movimento: há uma retomada do já dito, com propósitos de ressignificação e, em seguida, um movimento de avanço, com o acréscimo da informação nova, que é a mais saliente e, nesse caso, mais surpreendente. Esses movimentos de retomada e de avanço ajudam a caracterizar relações de dependência entre as orações envolvidas, corroborando o caráter segmentado (ou hipotático, nos moldes de Halliday) das construções com no que.

(25) Hoje cheguei na escola, iria ser um dia normal, pensei eu, [no que chego $] \mathrm{O}_{1},[$ me deparo com minhas amigas, renata, francine, jéssica, todas chorando $\mathrm{O}_{2}$. (gaabyparis $\left.1 . b l o g s p o t . c o m . b r\right)$

(26) (...) aí diz que essa luz ela deu uma apagada e acendeu de novo aí [no que ela acendeu $] \mathrm{O}_{1}$ [ela saiu... $] \mathrm{O}_{2}$ como se fosse na velocidade da luz sentido... (Iboruna/AC-035)

(27) Tinha nadado cerca de 40 minutos, quando voltava para a margem parei de bater as pernas. [No que parei $] \mathrm{O}_{1}$, [senti a mordida $] \mathrm{O}_{2}$. $(\mathrm{m} . \mathrm{g} 1$. globo.com)

(28) Levaram-no à Sloane Street e estacionaram perto da Harvey Nichols. [No que ele desceu do carro] $\mathrm{O}_{1}$, [todas as cabeças se viraram para fitá-lo, e várias pessoas começaram a rir e até gargalhar $] \mathrm{O}_{2}$ (charllescampos.blospot.com.br)

(29) Tomei, eu dei um passo e tomei uma bordoada na cabeça e daí, por imediato, eu lembro que daí, eu não posso the precisar, [no que 
eu tomei a paulada, $] \mathrm{O}_{1}$ [eu virei para o lado instantaneamente $] \mathrm{O}_{2}, \mathrm{o}$ cacique, que se intitulava o cacique, colocar o pau para trás, a madeira que ele estava na mão e foi o momento que eu também efetuei o disparo. [s.conjur.com.br]

(30) Então que eu fui na C\&A do centro na hora do almoço atrás de uma calça social da coleção, mas [no que eu chego lá $] \mathrm{O}_{1}[$ não tinha mais (quase) $N A D A ! \mathrm{O}_{2}$ (ospobrestambemcompram.wordpress.com)

A retomada traz uma ressignificação do já dito, que é colocado em outras bases pelo enunciador. Mais propriamente, a informação retomada é colocada num cenário de suspense ou expectativa, criado em torno do que vai ser dito na sequência, de modo a direcionar a atenção do interlocutor para o que estará em foco. Portanto, argumentativamente, a construção põe em evidência, dramatiza ou focaliza o conteúdo subsequente. Em outras palavras, trata-se de um modo enfático de dizer, que é diferente daquele das construções com quando. A estrutura temático-informacional dos enunciados, em termos da articulação entre tema/propósito e dado/novo, está a serviço dessa ênfase. Nesse sentido, é possível afirmar que no que confere à $\mathrm{O}_{2}$ um peso argumentativo.

\section{Considerações finais}

A constituição de no que como juntor é um processo em pleno movimento. Os dados investigados, oriundos de enunciações faladas e escritas, permitiram apreender aspectos das reanálises categorial e semântica, que pressupõem perdas e ganhos, tão fundamentais para a formação da categoria conjuncional. Mostrei que a reorganização das fronteiras constituintes, o descarte de material morfológico não relevante para a configuração do novo juntor e a expansão dos significados são indícios fortes desse movimento. Além das análises de forma e de significado, lancei mão de parâmetros relativos à progressão temática e à distribuição de informação para evidenciar a singularidade do jogo argumentativo de no que, que tem a propriedade pragmática de pôr em foco ou "dramatizar" o segundo membro da construção. Dado o ineditismo desse objeto de investigação, o presente trabalho pretende contribuir para os estudos do português brasileiro que, em perspectiva sincrônica, aliam junção e gramaticalização. 
$\mathrm{O}$ trabalho corroborou as pesquisas que sustentam a categoria de Tempo como fonte produtiva para significados conjuncionais. Conforme argumentei, o tipo de relação temporal veiculado por no que é fundamental para explicar as implicaturas de causa e de condição. Os dados sugerem que, dentre as relações temporais instauradas, é a relação de Anterioridade Imediata (Imante) que preferencialmente alimenta a implicatura de causa; e a relação de Contingência, a implicatura de condição. Ambos os sentidos de causa e de condição são conversacionais, pragmáticos, dependentes do contexto. Considerando, juntamente com Kortmann (1997), que as relações temporais são mais primitivas, mais básicas, ao passo que as causais e condicionais são cognitivamente mais complexas e mais subjetivas, os trânsitos metafóricos Tempo $>$ Causa e Tempo $>$ Condição se conformam a um cline de gramaticalidade ${ }^{15}$ que aponta para o aumento de complexidade e de subjetividade, confirmando tendências na gramaticalização de juntores (TRAUGOTT; KÖNIG, 1991; TRAUGOTT; DASHER, 2002; KORTMANN, 1997).

\section{Referências}

ALI, M. S. Gramática histórica da língua portuguesa. São Paulo: Melhoramentos, 1964.

AMORIM, F. S. Gramaticalização em sincronia: o caso do conector por causa que. Cadernos de Letras da UFF, v. 47, 2013, p. 45-65.

BALLY, C. Linguistique générale et linguistique française. 4. ed. Berne: Éditions Francke, 1965.

BEGUELIN, M. J.; AVANZI, M.; CORMINBOEUF, G. (Eds.). La Parataxe. Tome 1: Entre dépendance et intégration. Berne: Peter Lang, 2010. (Collection Sciences pour la communication).

CÂMARA, J. M. História e estrutura da língua portuguesa. Rio de Janeiro: Padrão Livraria Editora, 1979.

\footnotetext{
${ }^{15}$ Nos estudos em gramaticalização, a grande flutuação de forma e de função é capturada por meio de representações escalares do tipo cline, que têm consequências distintas, a depender da perspectiva sincrônica ou diacrônica (HOPPER; TRAUGOTT, 1993). Na sincrônica, o cline permite arranjar os diferentes padrões de um item ou construção em função do aumento de gramaticalidade. Neste trabalho, privilegio um cline de gramaticalidade que contempla os trânsitos de sentidos.
} 
COUPER-KUHLEN, E.; KORTMANn, B. Cause, Condition, Concession, Contrast: Cognitive and Discourse Perspective. Berlim; New York: Mouton de Gruyter, 2000.

DIEWALD, G. A Model for Relevant Types of Contexts in Grammaticalization. In: WISCHER, I. (Ed.). New reflections on grammaticalization. Philadelphia: John Benjamins Publishing Company, 2002. p.103-120.

HAGÈGE, C. Les processus de grammaticalisation. In: HASPELMATH, M.; KÖNIG, E.; ÖESTERREICHER, W.; RAIBLE, W. (Eds.). Language Typology and Language Universals. Berlin; New York: Walter Gruyter, 2001. p. 1609-1623.

HALLIDAY, M. A. K. An Introduction to Functional Grammar. London: Edward Arnold, 1985.

HEINE, B. On the Role of Context in Grammaticalization. In: WISCHER, I. (Ed.). New Reflections on Grammaticalization. Philadelphia: John Benjamins Publishing Company, 2002. p. 83-102.

HEINE, B. Grammaticalization. In: JOSEPH, B.; JANDA, R. (Eds.). The Handbook of Historical Linguistics. Oxford: Blackwell Publishing, 2003.

HEINE, B.; KUTEVA, T. The Genesis of Grammar: a Reconstruction. Studies in the Evolution of Language. New York: Oxford University Press, 2007.

HOPPER, P.; TRAUGOTT, E. Grammaticalization. Cambridge: Cambridge University Press, 1993.

JIMÉNEZ, A. N. Las subordinadas adverbials impropias do español. Málaga: Editorial Librería Ágora, 1990

KABATEK, J. Tradiciones discursivas y cambio linguístico. Lexis XXIX, 2, 2005, p.151-177.

KORTMANN, B. Adverbial Subordination: a Typology and History of Adverbial Subordinators Based on European Languages. Berlin: Mouton de Gruyter, 1997.

LONGHIN-THOMAZI, S. R. Flutuação e gramaticalização no paradigma dos juntores em português: forma, significado e história de (na) hora que. Filologia e linguística portuguesa, n. 13, 2011, p.147-166.

MEILLET, A. Linguistique historique et linguistique générale. Paris: Libraire Honoré Champion, 1912. 
MOESCHLER, J.; REBOUL, A. Dictionnaire Encyclopédique de Pragmatique. Paris: Éditions du Seuil, 1994. p. 447-470.

MOSCOW, V. Conditional Constructions. In: HASPELMATH, M.; KÖNIG, E.; ÖESTERREICHER, W.; RAIBLE, W. (Eds.). Language Typology and Language Universals. Berlin; New York: Walter Gruyter, 2001. p. 998-1011.

PAIVA, M. C.; BRAGA, M. L. Juxtaposition et coordination: deux formes de parataxe? In: BÉGUELIN, M. J.; AVANZI, M.; CORMINBOEUF, G. (Eds.). La Parataxe. Tome 1: Entre dépendance et intégration. Berne: Peter Lang, 2010. p. 313-332. (Collection Sciences pour la communication).

PAIVA, M. C.; PEREIRA, M. Estatuto sintático das orações introduzidas pelas construções (prep) $+\operatorname{det}+\mathrm{N}$ temporal $+($ prep $)+$ que. Juiz de Fora, Veredas, v. 8, n. 1 e 2, 2004, p. 245-258.

PRINCE, E. Toward a Taxonomy of Given/New Information? In: COLE, P. (Ed.). Radical Pragmatics. New York: Academic Press, 1981.

RAIBLE, W. Linking Clauses. In: HASPELMATH, M.; KÖNIG, E.; ÖESTERREICHER, W.; RAIBLE, W. (Eds.). Language Typology and Language Universals. Berlin; New York: Walter Gruyter, 2001. 590617.

ROHDENBURG, G. On the History and Present Behavior of Subordinating that with Adverbial Conjunctions in English. In: SEONE, E.; LÓPEZ-COUSO, M. J. (Eds.). Theoretical and Empirical Issues in Grammaticalization. Amsterdam; Philadelphia: John Benjamins Publishing. Company, 2008, p.314-330.

TABOADA, M. Implicit and explicit coherence relations. In: RENKEMA, J. (Ed.). Discourse, of Course: an Overview of Research in Discourse Studies. Amsterdam; Philadelphia: John Benjamins Publishing Company, 2009. p. 127-140.

TRAUGOTT, E.; KÖNIG, E. The Semantic-Pragmatics of Grammaticalization Revisited. In: TRAUGOTT, E.; HEINE, B. (Eds.). Approaches to Grammaticalization. Amsterdam; Philadelphia: John Benjamins Publishing Company, 1991. p. 189-218.

TRAUGOTT, E.; DASHER, R. Regularity in Semantic Change. Cambridge: Cambridge University Press, 2002. 
TRAUGOTT, E. Grammaticalization and Mechanisms of Change. In: NARROG, H.; HEINE, B. (Eds.). The Oxford Handbook of Grammaticalization. New York: Oxford University Press, 2011. p. 19-30. TRAUGOTT, E. The Status of Onset Contexts in Analysis of Microchanges. In: Kytö, M. (Ed.). English Corpus Linguistics: Crossing Paths. Amsterdam; New York: Rodopi, 2012. p. 255-289.

ZIV, Yael. 'Causality and context dependence'. Belgian Journal of Linguistics, n. 8, 1993, p. 187-200. 
